\title{
Association of Longitudinal Changes in Drusen Characteristics and Retinal Layer Volumes with Subsequent Subtype of Choroidal Neovascularisation
}

\author{
Ali Lamin ${ }^{a, b}$ Amgad El Nokrashy $^{c}$ Shruti Chandra, ${ }^{a, b}$ Sobha Sivaprasad ${ }^{a, b}$ \\ a NIHR Moorfields Biomedical Research Centre, Moorfields Eye Hospital NHS Foundation Trust, London, UK; \\ ${ }^{b}$ UCL Institute of Ophthalmology, London, UK; ' Mansoura Ophthalmic Centre, Mansoura University, Mansoura, \\ Egypt
}

\section{Keywords}

Age-related macular degeneration - Choroidal

neovascularisation type · Drusen load · Retinal layer

volumes $\cdot$ Imaging biomarkers

\begin{abstract}
Aim: To investigate the longitudinal correlation between drusen characteristics and retinal layer volumes pre conversion and subsequent type of choroidal neovascularisation (CNV). Methods: This was a single-centre retrospective study. The study participants were patients with wet agerelated macular degeneration (AMD) in one eye who developed wet AMD in the contralateral eye, with at least 2 years of follow-up prior to conversion. The Moorfields Eye Hospital database was searched for eligible patients and their data were recorded. Eyes were classified as occult or classic based on fundus fluorescein angiography. Optical coherence tomography (OCT) images were analysed for drusen characteristics and retinal layer volumes were analysed over time using automated software (Topcon 3D OCT-2000 and Orion, Voxeleron LLC, respectively). All values were obtained at
\end{abstract}

baseline as well as year 1 and year 2 before conversion to wet AMD. Results: Fifty-one eyes with bilateral CNV showed high correlation of type of CNV between eyes (kappa statistic 0.89). A total of 49 wet AMD eyes ( 29 occult, 20 classic) were analysed for drusen parameters. Two patients with retinal angiomatous proliferation were excluded. Drusen count, area, and volume did not differ by CNV type, but the rates of change of drusen area $(p=0.046)$ and drusen volume $(0.022)$ were higher in the occult group in the year preceding CNV development. Of the 49 eyes, 17 (10 occult, 7 classic) with available good quality OCT were analysed for retinal layer volumes. There was a progressive reduction in outer nuclear layer (ONL) volume $(p=0.002)$ and an expansion in outer plexiform layer volume $(p=0.015)$ in eyes that developed occult CNV. Conclusion: Our study shows that rate of increase in drusen load and reduction in ONL are significant features seen in eyes developing occult CNV, highlighting new imaging markers that need to be replicated in larger studies. These markers provide insight into the pathogenesis of CNV and may serve as prognostic indicators, as classic CNV carries a poorer prognosis compared to occult CNV.

(c) 2020 S. Karger AG, Basel karger@karger.com

www.karger.com/ore

Karger'? (c) 2020 S. Karger AG, Base

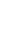

Sobha Sivaprasad

NIHR Moorfields Biomedical Research Centre

Moorfields Eye Hospital NHS Foundation Trust

162 City Road, London EC1V 2PD (UK)

E-Mail sobha.sivaprasad@nhs.net 


\section{Introduction}

Age-related macular degeneration (AMD) is a leading cause of severe vision loss in people over the age of 50 years in developed countries $[1,2]$. There are two main forms of the disease: the dry form (including early and intermediate AMD and an advanced form termed geographic atrophy) and the wet form. Wet AMD develops when new choroidal blood vessels grow and break through Bruch's membrane (BM) and/or the retinal pigment epithelium (RPE). This phenomenon is defined as choroidal neovascularisation (CNV). CNV occurs in approximately $10-15 \%$ of all AMD cases, and these eyes are at high risk of severe visual loss because it often results in elevation or penetration through the RPE with adjacent suband intraretinal fluid and haemorrhage [3]. CNV can be classified based on fluorescence angiography into occult, classic, or mixed lesion types [4]. Classic lesions are often aggressive with early and severe loss of vision, while occult lesions are often stable with less visual loss [5].

It is important to distinguish between occult and classic CNV lesions because the natural course of the disease and its prognosis and benefit from certain treatments vary between different types of CNV $[6,7]$. This was specifically realised when photodynamic therapy or laser treatment were the first lines of treatment. Photodynamic therapy has been established only for those lesions that are predominantly classic CNV [8], while laser photocoagulation has been used mainly for those lesions that have some evidence of classic CNV [4]. Furthermore, the importance of classifying CNV lesions as classic or occult has also been used recently reported in the anti-VEGF era in the MARINA and ANCHOR trials that assessed ranibizumab as intravitreal treatment of CNV secondary to AMD. The MARINA trial was for occult CNV [9], whereas the ANCHOR trial was for predominantly classic lesions [10]. Currently, the clinical relevance of CNV classification in wet AMD eyes is uncertain. This is because anti-VEGF agents were found to be effective in treating $\mathrm{CNV}$ regardless of its type [11]. However, classic CNV is associated with poor prognosis, risk of atrophy, and fibrosis after anti-VEGF therapy compared to occult CNV (CATT). New trials to test novel therapies also specify the CNV type among their inclusion criteria $[12,13]$. Thus, CNV classification will allow for more effective trials as prognosis and treatment may vary based on CNV type.

The risk of developing occult CNV in the second eye of patients with unilateral occult CNV has been found to be high [14]. Various studies on patients with unilateral CNV secondary to AMD have identified important risk factors for CNV development in the fellow eye [15-18]. The characteristics of drusen of the fellow eye are correlated with the type of CNV in the affected eye [19-21]. For example, occult CNV is more likely to be associated with intermediate drusen than pure classic CNV that may occur in eyes with no or small drusen [21]. However, very few studies have investigated the correlation between clinical characteristics such as drusen load preceding $\mathrm{CNV}$ development in the same eye. We reported that the mean change in macular drusen load in eyes that converted to wet $A M D$ increased a year before conversion to wet AMD [22].

In this study we investigated a cohort of patients who underwent treatment for unilateral $\mathrm{CNV}$ and developed $\mathrm{CNV}$ in the fellow eye at the end of the 2-year study period. In the fellow eye, automated drusen and retinal layer quantification measurements were obtained from spectral-domain optical coherence tomography (OCT) scans prior to conversion onset. The aim of this study was to investigate whether any correlation existed between these parameters and the subsequent CNV type in the same eye (i.e., fellow eyes). We also investigated the correlation in CNV type between the two eyes in these patients as it is known that drusen phenotypes are similar between eyes. Thus, we hypothesised that certain drusen or retinal layer quantification parameters may indeed better explain the symmetry of type of bilateral CNV.

\section{Materials and Methods}

\section{Data Collection}

Consecutive fluorescein angiography (FA) and OCT images of patients with unilateral wet AMD were reviewed from the database of Moorfields Eye Hospital. For inclusion in this study, patients were required to have $\mathrm{CNV}$ in one eye as evidenced by FA and to have developed a CNV lesion in the fellow eye with at least 2 years of follow-up before developing the lesion. We excluded all patients with polypoidal choroidal vasculopathy, subfoveal fibrosis, or ungradable CNV due to haemorrhage or poor imaging quality. Eyes with CNV secondary to other causes rather than AMD or without available FA images were also excluded.

\section{Image Grading}

CNV lesions were classified independently by two ophthalmologists (A.L. and A.E.N.) for each patient on the basis of early, mid, and late frames of FA. The CNV type was classified based on FA as occult, classic, or retinal angiomatous proliferation (RAP). Mixed lesions were classified as classic CNV. Any discrepancies between the two ophthalmologists were resolved by a third expert consultant (S.S.)

The drusen characteristics in the fellow eye of each patient were determined using the drusen quantification software available on the Topcon 3D OCT-2000 device (Topcon, Tokyo, Japan). Drusen 
measurements including drusen count, area, and volume were collected retrospectively at baseline, year 1 , and year 2 .

Macular OCT images were acquired from the fellow eyes using a $6 \times 6 \mathrm{~mm}$ macular cube scan (3D OCT, Topcon). Each fellow eye was part of a 3 scans/2 years protocol (baseline, year 1 , and year 2). Macular layer volumes were derived for circles of 3 and $6 \mathrm{~mm}$ diameter around the foveal centre using an automated layer segmentation software (Orion, Voxeleron LLC). The following layer volumes were derived: retinal nerve fibre layer, ganglion cell-inner plexiform layer, inner nuclear layer (INL), outer nuclear layer (ONL), photoreceptors, RPE-BM, and total retinal volume.

\section{Statistical Analysis}

Statistical analysis was performed using SPSS software version 24. Normality was tested by the Shapiro-Wilk test. As the data were not normally distributed, nonparametric $t$ tests (Mann-Whitney $\mathrm{U}$ and Wilcoxon signed-rank test) were used to compare the differences in drusen parameters and retinal layer volumes between the classic and occult types. Agreement of CNV type between the two eyes in cases where the fellow eye developed CNV was quantified with the kappa statistic. $p$ values $\leq 0.05$ were considered statistically significant.

\section{Results}

\section{Demographic Features of the Participants}

A total of 209 patients with unilateral wet AMD and available FA were identified. Seventy patients met the inclusion criteria. Of these 70 patients, 19 were excluded due to absence of FA in the fellow eye. In the remaining 51 patients' fellow eyes, 29 were classified with occult CNV, 20 with classic CNV, and 2 with RAP type. As RAP lesions were rare, we only compared the differences in the quantifications of drusen load and retinal layer volume between the classic and occult types.

For drusen load quantifications, the whole cohort of 29 occult CNVs and 20 classic CNVs were included in the study. For occult lesion participants, the mean (SD) age of 22 females $(75 \%)$ and 7 males $(25 \%)$ was $75.7(7.5)$ years, ranging from 60 to 88 years. For classic lesion participants, the mean (SD) age of 14 females (70\%) and 6 males (30\%) was 75.8 (6.5) years, ranging from 65 to 85 years.

For retinal layer segmentation analysis, only 17 participants were included (10 occult and 7 classic). The other participants were excluded because their macular OCT images of the 2-year protocol were not available. For occult lesion participants, the mean (SD) age of 7 females (70\%) and 3 males (30\%) was 82.4 (7.6) years, ranging from 71 to 93 years. For classic lesion participants, the mean (SD) age of 4 females (57\%) and 3 males (43\%) was 80.2 (7.5) years, ranging from 71 to 91 years.

Correlation between Imaging Biomarkers and CNV Subtype
Table 1. Drusen parameters in AMD eyes prior to conversion to either occult $(n=29)$ or classic $(n=20) \mathrm{CNV}$

\begin{tabular}{|c|c|c|c|}
\hline Drusen parameter & Occult & Classic & $p$ value \\
\hline \multicolumn{4}{|l|}{ Drusen count } \\
\hline Baseline & $9.93(8)$ & $8.50(5.7)$ & 0.729 \\
\hline Year 1 & $11.48(7.8)$ & $9.85(6)$ & 0.561 \\
\hline Year 2 & $11.69(8.8)$ & $11.65(7)$ & 0.791 \\
\hline \multicolumn{4}{|l|}{ Drusen area, $\mathrm{mm}^{2}$} \\
\hline Baseline & $1.49(1.2)$ & $1.77(1.38)$ & 0.483 \\
\hline Year 1 & $1.84(1.48)$ & $2.21(1.7)$ & 0.528 \\
\hline Year 2 & $2.63(1.8)$ & $2.46(1.8)$ & 0.707 \\
\hline \multicolumn{4}{|l|}{ Drusen volume, $\mathrm{mm}^{3}$} \\
\hline Baseline & $0.070(0.07)$ & $0.078(0.06)$ & 0.464 \\
\hline Year 1 & $0.085(0.089)$ & $0.104(0.084)$ & 0.309 \\
\hline Year 2 & $0.131(0.114)$ & $0.118(0.1)$ & 0.640 \\
\hline \multicolumn{4}{|c|}{ Change in drusen area, $\mathrm{mm}^{2}$} \\
\hline Baseline to year 1 & $0.354(0.61)$ & $0.44(0.89)$ & 0.855 \\
\hline Year 1 to year 2 & $0.788(0.8)$ & $0.252(0.7)$ & 0.046 \\
\hline \multicolumn{4}{|c|}{ Change in drusen volume, $\mathrm{mm}^{3}$} \\
\hline Baseline to year 1 & $0.014(0.02)$ & $0.026(0.04)$ & 0.784 \\
\hline Year 1 to year 2 & $0.046(0.04)$ & $0.013(0.03)$ & 0.022 \\
\hline
\end{tabular}

Values for occult and classic CNV are presented as mean (SD).

\section{Drusen Load prior to CNV Development}

Table 1 shows the means and SDs of drusen load including count, area, and volume at baseline, year 1, and year 2 and longitudinal change in drusen area and volume from baseline to year 1 and from year 1 to year 2 . While drusen parameters (count, area, volume) were alike in both CNV groups, the rates of change of drusen area and drusen volume were higher in the occult group in the year preceding CNV development.

\section{Retinal Layer Volumes prior to CNV Development}

Table 2 shows the means and SDs for the various layer volumes for 17 participants preceding CNV development. There were statistically significant differences between eyes with the two CNV types in mean ONL volume $(3 \mathrm{~mm})$. The ONL volume was thinner in eyes preceding classic CNV than occult CNV at baseline and year 1, indicating early decrease in photoreceptor volume in eyes that progress to classic CNV type. Otherwise, no significant differences were found between the two CNV lesions in volumes of other retinal layers.

Table 3 shows the longitudinal change of retinal layer volumes at 3 and $6 \mathrm{~mm}$ from baseline to year 1 and from year 1 to year 2 in occult and classic CNV lesions. From baseline to year 1, no differences were found between the 
Table 2. Mean retinal layer volumes at 3 and $6 \mathrm{~mm}$ in AMD eyes prior to conversion to either occult $(n=10)$ or classic $(n=7) \mathrm{CNV}$

\begin{tabular}{|c|c|c|c|c|c|c|c|}
\hline \multirow{2}{*}{$\begin{array}{l}\text { Retinal } \\
\text { layer }\end{array}$} & \multirow{2}{*}{$\begin{array}{l}\text { Time } \\
\text { line }\end{array}$} & \multicolumn{3}{|c|}{ Mean retinal layer volume at $3 \mathrm{~mm}$} & \multicolumn{3}{|c|}{ Mean retinal layer volume at $6 \mathrm{~mm}$} \\
\hline & & occult & classic & $p$ value & occult & classic & $p$ value \\
\hline \multirow[t]{3}{*}{ TRV } & baseline & $2.19(0.19)$ & $2.07(0.12)$ & 0.118 & $8.32(0.65)$ & $7.92(0.48)$ & 0.283 \\
\hline & year 1 & $2.17(0.18)$ & $2.03(0.12)$ & 0.118 & $8.24(0.62)$ & $7.85(0.54)$ & 0.283 \\
\hline & year 2 & $2.17(0.18)$ & $2.03(0.12)$ & 0.172 & $8.27(0.62)$ & $7.88(0.54)$ & 0.283 \\
\hline \multirow[t]{3}{*}{ RNFL } & baseline & $0.215(0.03)$ & $0.200(0.02)$ & 0.205 & $1.19(0.17)$ & $1.11(0.23)$ & 0.283 \\
\hline & year 1 & $0.206(0.04)$ & $0.196(0.02)$ & 0.770 & $1.16(0.19)$ & $1.06(0.22)$ & 0.495 \\
\hline & year 2 & $0.217(0.02)$ & $0.196(0.03)$ & 0.283 & $1.15(0.14)$ & $1.05(0.31)$ & 0.495 \\
\hline \multirow[t]{3}{*}{ GCIPL } & baseline & $0.508(0.07)$ & $0.511(0.04)$ & 0.845 & $1.75(0.24)$ & $1.76(0.13)$ & 0.558 \\
\hline & year 1 & $0.508(0.08)$ & $0.498(0.04)$ & 1 & $1.73(0.18)$ & $1.73(0.13)$ & 0.922 \\
\hline & year 2 & $0.526(0.07)$ & $0.500(0.07)$ & 0.558 & $1.82(0.20)$ & $1.74(0.17)$ & 0.283 \\
\hline \multirow[t]{3}{*}{ INL } & baseline & $0.301(0.03)$ & $0.278(0.02)$ & 0.143 & $1(0.08)$ & $0.90(0.06)$ & 0.435 \\
\hline & year 1 & $0.301(0.03)$ & $0.269(0.02)$ & 0.143 & $1(0.08)$ & $0.96(0.09)$ & 0.696 \\
\hline & year 2 & $0.288(0.03)$ & $0.270(0.02)$ & 0.380 & $0.99(0.09)$ & $0.96(0.07)$ & 0.696 \\
\hline \multirow[t]{3}{*}{ OPL } & baseline & $0.161(0.04)$ & $0.183(0.04)$ & 0.380 & $0.592(0.13)$ & $0.623(0.11)$ & 0.626 \\
\hline & year 1 & $0.156(0.03)$ & $0.190(0.06)$ & 0.435 & $0.577(0.10)$ & $0.627(0.11)$ & 0.380 \\
\hline & year 2 & $0.186(0.04)$ & $0.182(0.04)$ & 0.922 & $0.648(0.12)$ & $0.624(0.11)$ & 0.696 \\
\hline \multirow[t]{3}{*}{ ONL } & baseline & $0.689(0.06)$ & $0.589(0.06)$ & 0.011 & $2.47(0.24)$ & $2.21(0.23)$ & 0.064 \\
\hline & year 1 & $0.686(0.08)$ & $0.576(0.07)$ & 0.015 & $2.48(0.27)$ & $2.24(0.24)$ & 0.079 \\
\hline & year 2 & $0.626(0.08)$ & $0.584(0.08)$ & 0.495 & $2.34(0.28)$ & $2.27(0.28)$ & 0.558 \\
\hline \multirow[t]{3}{*}{ PR } & baseline & $0.318(0.02)$ & $0.306(0.02)$ & 0.495 & $1.29(0.11)$ & $1.23(0.10)$ & 0.435 \\
\hline & year 1 & $0.316(0.02)$ & $0.304(0.02)$ & 0.380 & $1.28(0.09)$ & $1.21(0.09)$ & 0.172 \\
\hline & year 2 & $0.325(0.03)$ & $0.302(0.02)$ & 0.172 & $1.30(0.09)$ & $1.22(0.09)$ & 0.172 \\
\hline \multirow[t]{3}{*}{ RPE-BM } & baseline & $0.047(0.02)$ & $0.048(0.06)$ & 0.329 & $0.137(0.03)$ & $0.157(0.07)$ & 0.696 \\
\hline & year 1 & $0.048(0.02)$ & $0.054(0.06)$ & 0.495 & $0.135(0.04)$ & $0.171(0.08)$ & 0.283 \\
\hline & year 2 & $0.067(0.04)$ & $0.068(0.05)$ & 0.845 & $0.152(0.05)$ & $0.200(0.07)$ & 0.172 \\
\hline
\end{tabular}

Values for occult and classic mean retinal layer volume are presented as mean (SD). GCIPL, ganglion cellinner plexiform layer; INL, inner nuclear layer; ONL, outer nuclear layer; OPL, outer plexiform layer; PR, photoreceptors; RNFL, retinal nerve fibre layer; RPE-BM, retinal pigment epithelium-Bruch's membrane; TRV, total retinal volume.

two CNV types or even within each CNV group. From year 1 to year 2, most of the retinal layer volume changes were observed in the outer retina, particularly in the occult group. There were significant differences between the two CNV groups in longitudinal ONL ( 3 and $6 \mathrm{~mm}$ ) and outer plexiform layer (OPL) volume $(3 \mathrm{~mm})$. There was a progressive reduction in ONL volume and an expansion in OPL volume in eyes that developed occult CNV.

In the occult CNV group, INL ( $3 \mathrm{~mm}$ ) and ONL volumes ( 3 and $6 \mathrm{~mm}$ ) decreased significantly from year 1 to year 2 . In contrast, there were significant increases in mean OPL (3 and $6 \mathrm{~mm}$ ) and RPE-BM ( $3 \mathrm{~mm}$ ) volumes from year 1 to year 2 . In the classic CNV group, only RPE$\mathrm{BM}$ volume $(6 \mathrm{~mm})$ increased significantly from year 1 to year 2.

\section{Correlation in CNV Type between the Two Eyes}

Table 4 summarises CNV types in patients with bilateral CNV. Of the 51 patients with bilateral CNV, 48 (94\%) had similar CNV types in both eyes: 27 patients had occult CNV in both eyes, 19 had classic lesions in both eyes, and 2 had RAP lesions in both eyes. The kappa statistic was 0.89 (95\% CI 0.76-1.0), indicating a strong level of agreement between the two eyes. 
Table 3. Longitudinal change in retinal layer volumes at 3 and $6 \mathrm{~mm}$ in AMD eyes prior to conversion to either occult $(n=10)$ or classic $(n=7) \mathrm{CNV}$

\begin{tabular}{|c|c|c|c|c|c|c|c|}
\hline \multirow{2}{*}{$\begin{array}{l}\text { Retinal layer } \\
\text { volume }\end{array}$} & \multirow[t]{2}{*}{ CNV subtype } & \multicolumn{3}{|c|}{ Year 1 volume change } & \multicolumn{3}{|c|}{ Year 2 volume change } \\
\hline & & mean $\left(\mathrm{mm}^{3}\right)$ & $p$ value $^{\mathrm{a}}$ & $p$ value $^{\mathrm{b}}$ & mean $\left(\mathrm{mm}^{3}\right)$ & $p$ value $^{\mathrm{a}}$ & $p$ value $^{b}$ \\
\hline \multicolumn{8}{|c|}{ Circle diameter $3 \mathrm{~mm}$} \\
\hline TRV & $\begin{array}{l}\text { occult } \\
\text { classic }\end{array}$ & $\begin{array}{l}-0.0189 \\
-0.0357\end{array}$ & $\begin{array}{l}0.059 \\
0.128\end{array}$ & 0.380 & $\begin{array}{c}-0.048 \\
0.03\end{array}$ & $\begin{array}{l}0.721 \\
0.735\end{array}$ & 0.626 \\
\hline RNFL & $\begin{array}{l}\text { occult } \\
\text { classic }\end{array}$ & $\begin{array}{l}-0.089 \\
-0.042\end{array}$ & $\begin{array}{l}0.203 \\
0.612\end{array}$ & 1 & $\begin{array}{l}0.011 \\
0.008\end{array}$ & $\begin{array}{l}0.285 \\
1\end{array}$ & 0.770 \\
\hline GCIPL & $\begin{array}{l}\text { occult } \\
\text { classic }\end{array}$ & $\begin{array}{l}-0.004 \\
-0.0134\end{array}$ & $\begin{array}{l}0.878 \\
0.499\end{array}$ & 0.696 & $\begin{array}{l}0.017 \\
0.02\end{array}$ & $\begin{array}{l}0.333 \\
0.612\end{array}$ & 0.329 \\
\hline INL & $\begin{array}{l}\text { occult } \\
\text { classic }\end{array}$ & $\begin{array}{r}0.007 \\
-0.091\end{array}$ & $\begin{array}{l}0.646 \\
0.176\end{array}$ & 0.118 & $\begin{array}{c}-0.0131 \\
0.01\end{array}$ & $\begin{array}{l}\mathbf{0 . 0 3 7} \\
0.866\end{array}$ & 0.143 \\
\hline OPL & $\begin{array}{l}\text { occult } \\
\text { classic }\end{array}$ & $\begin{array}{c}-0.052 \\
0.06\end{array}$ & $\begin{array}{l}0.333 \\
0.866\end{array}$ & 0.770 & $\begin{array}{r}0.029 \\
-0.077\end{array}$ & $\begin{array}{l}\mathbf{0 . 0 7} \\
1\end{array}$ & 0.015 \\
\hline ONL & $\begin{array}{l}\text { occult } \\
\text { classic }\end{array}$ & $\begin{array}{l}-0.029 \\
-0.0130\end{array}$ & $\begin{array}{l}0.959 \\
0.176\end{array}$ & 0.435 & $\begin{array}{c}-0.0599 \\
0.08\end{array}$ & $\begin{array}{l}\mathbf{0 . 0 5} \\
0.499\end{array}$ & 0.02 \\
\hline PR & $\begin{array}{l}\text { occult } \\
\text { classic }\end{array}$ & $\begin{array}{l}-0.021 \\
-0.020\end{array}$ & $\begin{array}{l}0.721 \\
0.735\end{array}$ & 0.770 & $\begin{array}{c}0.09 \\
-0.023\end{array}$ & $\begin{array}{l}0.646 \\
0.499\end{array}$ & 0.435 \\
\hline RPE-BM & $\begin{array}{l}\text { occult } \\
\text { classic }\end{array}$ & $\begin{array}{l}0.007 \\
0.05\end{array}$ & $\begin{array}{l}0.241 \\
0.063\end{array}$ & 1 & $\begin{array}{l}0.018 \\
0.014\end{array}$ & $\begin{array}{l}\mathbf{0 . 0 7} \\
0.063\end{array}$ & 0.495 \\
\hline \multicolumn{8}{|c|}{ Circle diameter $6 \mathrm{~mm}$} \\
\hline TRV & $\begin{array}{l}\text { occult } \\
\text { classic }\end{array}$ & $\begin{array}{l}-0.0845 \\
-0.0667\end{array}$ & $\begin{array}{l}0.093 \\
0.237\end{array}$ & 0.845 & $\begin{array}{l}0.0269 \\
0.0299\end{array}$ & $\begin{array}{l}0.721 \\
0.735\end{array}$ & 0.922 \\
\hline RNFL & $\begin{array}{l}\text { occult } \\
\text { classic }\end{array}$ & $\begin{array}{l}-0.0337 \\
-0.0466\end{array}$ & $\begin{array}{l}0.445 \\
0.237\end{array}$ & 0.770 & $\begin{array}{l}-0.024 \\
-0.099\end{array}$ & $\begin{array}{l}0.575 \\
0.735\end{array}$ & 0.845 \\
\hline GCIPL & $\begin{array}{l}\text { occult } \\
\text { classic }\end{array}$ & $\begin{array}{l}-0.0283 \\
-0.0311\end{array}$ & $\begin{array}{l}0.333 \\
0.237\end{array}$ & 0.922 & $\begin{array}{l}0.0907 \\
0.067\end{array}$ & $\begin{array}{l}0.114 \\
0.735\end{array}$ & 0.205 \\
\hline INL & $\begin{array}{l}\text { occult } \\
\text { classic }\end{array}$ & $\begin{array}{l}-0.041 \\
-0.073\end{array}$ & $\begin{array}{l}0.646 \\
1\end{array}$ & 0.696 & $\begin{array}{c}-0.0136 \\
0.00\end{array}$ & $\begin{array}{l}0.241 \\
0.735\end{array}$ & 0.435 \\
\hline OPL & $\begin{array}{l}\text { occult } \\
\text { classic }\end{array}$ & $\begin{array}{c}-0.0147 \\
0.048\end{array}$ & $\begin{array}{l}0.139 \\
0.866\end{array}$ & 0.558 & $\begin{array}{l}0.0714 \\
-0.033 \\
\end{array}$ & $\begin{array}{l}\mathbf{0 . 0 2 8} \\
0.866\end{array}$ & 0.118 \\
\hline ONL & $\begin{array}{l}\text { occult } \\
\text { classic }\end{array}$ & $\begin{array}{l}0.071 \\
0.0311\end{array}$ & $\begin{array}{l}0.646 \\
0.310\end{array}$ & 0.495 & $\begin{array}{r}-0.1417 \\
0.0298\end{array}$ & $\begin{array}{l}\mathbf{0 . 0 1 3} \\
0.499\end{array}$ & 0.025 \\
\hline PR & $\begin{array}{l}\text { occult } \\
\text { classic }\end{array}$ & $\begin{array}{l}-0.0109 \\
-0.0175\end{array}$ & $\begin{array}{l}0.333 \\
0.176\end{array}$ & 0.626 & $\begin{array}{l}0.0225 \\
0.066\end{array}$ & $\begin{array}{l}0.878 \\
1\end{array}$ & 1 \\
\hline RPE-BM & $\begin{array}{l}\text { occult } \\
\text { classic }\end{array}$ & $\begin{array}{c}-0.010 \\
0.0143\end{array}$ & $\begin{array}{l}0.575 \\
0.091\end{array}$ & 0.283 & $\begin{array}{l}0.0166 \\
0.0287\end{array}$ & $\begin{array}{l}0.074 \\
\mathbf{0 . 0 4 3}\end{array}$ & 0.558 \\
\hline
\end{tabular}

GCIPL, ganglion cell-inner plexiform layer; INL, inner nuclear layer; ONL, outer nuclear layer; OPL, outer plexiform layer; PR, photoreceptors; RNFL, retinal nerve fibre layer; RPE-BM, retinal pigment epitheliumBruch's membrane; TRV, total retinal volume. ${ }^{a}$ Wilcoxon signed-rank test for paired volume measurements, year 1 (baseline vs. year 1) and year 2 (year 1 vs. year 2). ${ }^{\text {b }}$ Mann-Whitney U test, occult versus classic. 
Table 4. CNV types in patients with bilateral CNV

\begin{tabular}{lcccc}
\hline \multirow{2}{*}{ CNV type in first eye } & \multicolumn{2}{c}{ CNV type in fellow eye } & \multirow{2}{*}{ Total } \\
\cline { 2 - 4 } & occult & classic & RAP & \\
\hline Occult & 27 & 1 & 0 & 28 \\
Classic & 2 & 19 & 0 & 21 \\
RAP & 0 & 0 & 2 & 2 \\
\hline Total & 29 & 20 & 2 & 51 \\
\hline
\end{tabular}

RAP, retinal angiomatous proliferation.

\section{Discussion}

In this study we compared the 2-year change in drusen load and retinal layer volumes between eyes that developed occult and classic CNV lesions at the end of the 2-year follow-up period. When comparing drusen load between the two CNV types, there were significant increases in drusen area and volume in the preceding 12 months prior to development of occult $\mathrm{CNV}$, whereas no significant differences were found in means of drusen count, area, or volume at baseline, year 1, or year 2 in the classic CNV eyes. When comparing retinal layer volumes between the two CNV types, thinning of baseline ONL was found in the classic CNV groups, and significant differences in volume changes of ONL and OPL were found between the two CNV groups in year 2 only (no differences between the two CNVs were found in year 1). In occult CNVs, ONL and INL volumes were found to be reduced, whereas OPL and RPE-BM volumes were found to be expanded from year 1 to year 2. In classic CNVs, only RPE-BM volume increased from year 1 to year 2 . We also investigated, in the same cohort, the agreement between $\mathrm{CNV}$ type in second eyes developing $\mathrm{CNV}$ and the first CNV eye. Agreement was high (kappa statistic 0.89).

The drusen load findings of our study support findings reported previously in the literature. It has been reported that the clinical features in the fellow eye correlate with the type of CNV in the affected eye in AMD patients with unilateral CNV using colour fundus photography [21, 23]. Abugreen et al. [21] found that the fellow eyes of occult CNV have significantly more severe AMD features compared to eyes with classic CNV. Similarly, Sivaprasad et al. [23] showed that this kind of association between the CNV type in the affected eye and the severity of the disease in the fellow eye can only be applied on Caucasians, compared to Chinese patients who did not show a similar disease pattern.
It is important to notice that the present study longitudinally investigated the correlation between prior drusen load quantifications using spectral-domain OCT and subsequent $\mathrm{CNV}$ type in the same eye. Our data showed that a greater increase in OCT drusen area and volume can be seen in the year before developing occult CNV compared to other eyes that developed classic CNV. As these drusen quantifications were measured by spectraldomain OCT, the scans only detected soft drusen, and no other type of drusen such as reticular pseudodrusen could be quantified. Thus, our findings of no significant differences between the two CNV groups by means of OCT drusen count, area, and volume at baseline, year 1, or year 2 are consistent with the recent work of Marsiglia et al. [19], who showed that soft drusen on colour photographs in one eye are not associated with CNV type in the other eye.

Our study demonstrated significant baseline thinning of the ONL in eyes that developed classic CNV. Thinning of the ONL in AMD eyes has been reported in recent studies using OCT that showed ONL thinning in eyes with intermediate AMD [24-26]. We also reported in a recent study that the ONL is either not affected at early AMD stages or the amount of damage is not significant to be detected at earlier stages of the disease [27]. Our finding suggests that the ONL degenerates earlier in eyes that will develop classic CNV type than occult one, but does not visibly worsen over time. Additional findings in this study support this hypothesis, which is a significant reduction in ONL volume in the eyes that developed occult CNV. Another notable observation in this study was that the OPL increased in volume in the occult type. OPL thickening with age and in AMD has been reported recently $[27,28]$. This increase in OPL volume may represent a compensatory expansion as a consequence of ONL thinning.

Finally, the observed symmetry in CNV types between the two eyes was high, and this may give us an idea of the likelihood symmetry between the two eyes when trying to predict the CNV type that will most likely develop in a fellow eye of a patient with unilateral wet AMD. The symmetry of CNV type between eyes of AMD patients has been reported previously in a study of 115 patients, which showed that patients with unilateral occult CNV have a high risk of developing occult CNV in the fellow eye [14]. However, a recent study reported poor agreement (kappa statistic 0.16 ) in the symmetry of CNV between the two eyes in patients with bilateral wet AMD [29]. It is possible that methodological differences explain the disagreement with the present study. 
To our knowledge, this is the first study to longitudinally investigate the difference in retinal layer volumes and drusen load between occult and classic CNV in order to identify imaging biomarkers. These biomarkers may aid in predicting the CNV type in AMD eyes before it develops. This will allow for more individualised patient care and more effective trials because prognosis and treatment may vary based on CNV type.

The limitations of this study include its retrospective nature; there was a possible ascertainment bias as we only included patients with active CNV undergoing treatment. Further longitudinal studies involving other factors such as subretinal drusenoid deposits, pigmentary changes, and choroidal thickness may enable the development of a risk score based on weight of evidence of each imaging marker.

In summary, the association between simple automated quantification of drusen and retinal layer volumes using the method described and subsequent CNV type would suggest that different pathogenetic mechanisms explain the development of occult or classic CNV. This hypothesis might have to be tested by further studies on larger patient cohorts. The observations of the present study provide imaging biomarkers that may help in predicting the type of CNV. Also, the strong agreement between $\mathrm{CNV}$ types with bilateral $\mathrm{CNV}$ is consistent with distinct pathogenetic mechanisms or patient-specific modifiers, with some patients being more at risk of one type than another, which may support separating these subgroups in future trials of novel therapies or treatment regimens.

\section{Acknowledgement}

The research was supported by the National Institute for Health Research (NIHR) Biomedical Research Centre based at Moorfields Eye Hospital NHS Foundation Trust and UCL Institute of Ophthalmology. The views expressed are those of the authors and not necessarily those of the NHS, the NIHR, or the Department of Health.

\section{Statement of Ethics}

This study was approved by the Ethical Review Board of Moorfields Eye Hospital and adhered to the principles of the Declaration of Helsinki.

\section{Disclosure Statement}

The authors have no conflicts of interest to declare.

\section{Funding Sources}

The authors received no funding for this study.

\section{Author Contributions}

A. Lamin designed the study, collected and analysed the data, and took the writing lead. A. El Nokrashy collected and analysed the data. S. Chandra analysed the data and edited the manuscript. Prof. S. Sivaprasad designed and directed the study. All authors discussed the results and commented on the manuscript.

\section{References}

1 Klaver CC, Wolfs RC, Vingerling JR, Hofman A, de Jong PT. Age-specific prevalence and causes of blindness and visual impairment in an older population: the Rotterdam Study. Arch Ophthalmol. 1998 May;116(5):653-8.

2 Buch H, Nielsen NV, Vinding T, Jensen GB, Prause JU, la Cour M. 14-year incidence, progression, and visual morbidity of age-related maculopathy: the Copenhagen City Eye Study. Ophthalmology. 2005 May;112(5):787-98.

3 Rosenfeld PJ, Brown DM, Heier JS, Boyer DS, Kaiser PK, Chung CY, et al.; MARINA Study Group. Ranibizumab for neovascular age-related macular degeneration. N Engl J Med. 2006 Oct;355(14):1419-31.

4 Laser photocoagulation of subfoveal neovascular lesions in age-related macular degeneration. Results of a randomized clinical trial. Macular Photocoagulation Study Group. Arch Ophthalmol. 1991 Sep;109(9):1220-31.

5 Bressler NM, Finklestein D, Sunness JS, Maguire AM, Yarian D. Retinal pigment epithe- lial tears through the fovea with preservation of good visual acuity. Arch Ophthalmol. 1990 Dec;108(12):1694-7.

6 Occult choroidal neovascularization. Influence on visual outcome in patients with agerelated macular degeneration. Macular Photocoagulation Study Group. Arch Ophthalmol. 1996 Apr;114(4):400-12.

7 Stevens TS, Bressler NM, Maguire MG, Bressler SB, Fine SL, Alexander J, et al. Occult choroidal neovascularization in age-related macular degeneration. A natural history study. Arch Ophthalmol. 1997 Mar;115(3):345-50.

8 Photodynamic therapy of subfoveal choroidal neovascularization in age-related macular degeneration with verteporfin: one-year results of 2 randomized clinical trials - TAP report. Treatment of age-related macular degeneration with photodynamic therapy (TAP) Study Group. Arch Ophthalmol. 1999 Oct;117(10):1329-45.

9 Chang TS, Bressler NM, Fine JT, Dolan CM, Ward J, Klesert TR. Improved vision-related function after ranibizumab treatment of neovascular age-related macular degeneration: results of a randomized clinical trial. Arch Ophthalmol. 2007 Nov;125(11):1460-9.

10 Brown DM, Kaiser PK, Michels M, Soubrane G, Heier IS, Kim RY, et al.; ANCHOR Study Group. Ranibizumab versus verteporfin for neovascular age-related macular degeneration. N Engl J Med. 2006 Oct;355(14):143244.

11 Invernizzi A, Nguyen V, Teo K, Barthelmes D, Fung A, Vincent A, et al. Five-Year RealWorld Outcomes of Occult and Classic Choroidal Neovascularization: Data From the Fight Retinal Blindness! Project. Am J Ophthalmol. 2019 Aug;204:105-12.

12 Danis R, McLaughlin MM, Tolentino $M$, Staurenghi G, Ye L, Xu CF, et al.; Pazopanib Eye Drops Study Group. Pazopanib eye drops: a randomised trial in neovascular agerelated macular degeneration. Br J Ophthalmol. 2014 Feb;98(2):172-8. 
13 Jaffe GJ, Ciulla TA, Ciardella AP, Devin F, Dugel PU, Eandi CM, et al. Dual Antagonism of PDGF and VEGF in Neovascular Age-Related Macular Degeneration: A Phase IIb, Multicenter, Randomized Controlled Trial. Ophthalmology. 2017 Feb;124(2):224-34.

14 Chang B, Yannuzzi LA, Ladas ID, Guyer DR, Slakter JS, Sorenson JA. Choroidal neovascularization in second eyes of patients with unilateral exudative age-related macular degeneration. Ophthalmology. 1995 Sep;102(9): 1380-6.

15 Roy M, Kaiser-Kupfer M. Second eye involvement in age-related macular degeneration: a four-year prospective study. Eye (Lond). 1990;4(Pt 6):813-8.

16 Five-year follow-up of fellow eyes of patients with age-related macular degeneration and unilateral extrafoveal choroidal neovascularization. Macular Photocoagulation Study Group. Arch Ophthalmol. 1993 Sep;111(9): 1189-99.

17 Pieramici DJ, Bressler SB. Age-related macular degeneration and risk factors for the development of choroidal neovascularization in the fellow eye. Curr Opin Ophthalmol. 1998 Jun;9(3):38-46.

18 Sandberg MA, Weiner A, Miller S, Gaudio AR. High-risk characteristics of fellow eyes of patients with unilateral neovascular age-related macular degeneration. Ophthalmology. 1998 Mar;105(3):441-7.
19 Marsiglia M, Boddu S, Chen CY, Jung JJ, Mrejen S, Gallego-Pinazo R, et al. Correlation between neovascular lesion type and clinical characteristics of nonneovascular fellow eyes in patients with unilateral, neovascular agerelated macular degeneration. Retina. 2015 May;35(5):966-74.

20 Pauleikhoff D, Barondes MJ, Minassian D, Chisholm IH, Bird AC. Drusen as risk factors in age-related macular disease. Am J Ophthalmol. 1990 Jan;109(1):38-43.

21 Abugreen S, Muldrew KA, Stevenson MR, VanLeeuwen R, DeJong PT, Chakravarthy U. CNV subtype in first eyes predicts severity of ARM in fellow eyes. Br J Ophthalmol. 2003 Mar;87(3):307-11.

22 Lamin A, Dubis AM, Sivaprasad S. Changes in macular drusen parameters preceding the development of neovascular age-related macular degeneration. Eye (Lond). 2019 Jun; 33(6):910-6.

23 Sivaprasad S, Membrey WL, Sivagnanavel V, Gonzalez JG, Liu DT, Chan WM, et al. Second eye of patients with unilateral neovascular age-related macular degeneration: caucasians vs Chinese. Eye (Lond). 2006 Aug;20(8):9236.

24 Schuman SG, Koreishi AF, Farsiu S, Jung SH, Izatt JA, Toth CA. Photoreceptor layer thinning over drusen in eyes with age-related macular degeneration imaged in vivo with spectral-domain optical coherence tomography. Ophthalmology. 2009 Mar;116(3):488496.e2.
25 Sadigh S, Cideciyan AV, Sumaroka A, Huang WC, Luo X, Swider M, et al. Abnormal thickening as well as thinning of the photoreceptor layer in intermediate age-related macular degeneration. Invest Ophthalmol Vis Sci. 2013 Mar;54(3):1603-12.

26 Brandl C, Brücklmayer C, Günther F, Zimmermann ME, Küchenhoff $\mathrm{H}$, Helbig $\mathrm{H}$, et al. Retinal Layer Thicknesses in Early Age-Related Macular Degeneration: Results From the German AugUR Study. Invest Ophthalmol Vis Sci. 2019 Apr;60(5):1581-94.

27 Lamin A, Oakley JD, Dubis AM, Russakoff DB, Sivaprasad S. Changes in volume of various retinal layers over time in early and intermediate age-related macular degeneration. Eye (Lond). 2019 Mar;33(3):428-34.

28 Nieves-Moreno M, Martínez-de-la-Casa JM, Morales-Fernández L, Sánchez-Jean R, SáenzFrancés F, García-Feijoó J. Impacts of age and sex on retinal layer thicknesses measured by spectral domain optical coherence tomography with Spectralis. PLoS One. 2018 Mar; 13(3):e0194169.

29 Mann SS, Rutishauser-Arnold Y, Peto T, Jenkins SA, Leung I, Xing W, et al. The symmetry of phenotype between eyes of patients with early and late bilateral age-related macular degeneration (AMD). Graefes Arch Clin Exp Ophthalmol. 2011 Feb;249(2):209-14. 